\title{
22. LA INDELEGABILIDAD DEL VOTO Y LA JUNTA DE PORTAVOCES
}

\author{
M. ${ }^{a}$ VICTORIA GARCÍA-ATANCE GARCÍA
}

Profesora Titular de Derecho Constitucional

UNED 


\section{SUMARIO}

INTRODUCCIÓN.-FUNCIONAMIENTO REAL DEL PRECEPTO 79-3.-1. El sistema de voto ponderado como exponente contra legem. 2. Su valoración en la doctrina. 3. Su representación en el ámbito parlamentario. OPCIÓN POR UN SISTEMA DE VOTO PERSONAL E INDELEGABLE. 


\title{
22. LA INDELEGABILIDAD DEL VOTO Y LA JUNTA DE PORTAVOCES
}

\author{
POR \\ M. VICTORIA GARCÍA-ATANCE GARCÍA \\ Profesora Titular de Derecho Constitucional \\ UNED
}

INTRODUCCIÓN

La institucionalización del Estado de Partidos se ha proyectado en el ámbito parlamentario configurando un Parlamento de carácter eminentemente grupal, superador del Parlamento individualizado del siglo $x \mid X$, que evidencia una sujeción de los parlamentarios que pertenecen a un mismo partido, a una disciplina y organización estable, proyectándose así en los Estados Demoliberales una especie de mandato imperativo ${ }^{1}$ de los Partidos politicos sobre sus parlamentarios y originando una especie de grupocracia ${ }^{2}$-en feliz expresión italiana- en la que el Parlamento se manifiesta "no tanto como una suma de Diputados y Senadores, sino como un conjunto de grupos parlamentarios" ${ }^{3}$.

En este modelo de Parlamento, la figura del individuo parlamentario asume frecuentemente un simple papel ratificador de las decisiones adoptadas por el grupo parlamentario al que pertenece. drid, 1991.

1 A. Torres del Moral: "El Estado español de partidos", R.C.E.C., n. ${ }^{\circ}$ 8, Ma-

2 Boccacinl: Sistema Politico e regolementi parlamentari. Milán, 1980, pág. 253.

3 E. Álvarez Conde: El régimen político español. Madrid. Tecnos, 1983, pág. 141. 
En este contexto, cualquier iniciativa legislativa o de enmienda es objeto de una rígida disciplina de grupo ${ }^{4}$. Esta disciplina interna que proyectan los partidos rígidos sobre sus parlamentarios, aunque tiene sus ventajas de operatividad y eficacia, no ha dejado por ello de tener una enérgica contestación en la doctrina ${ }^{5}$, al referirse a la paradoja que comporta el constitucionalismo actual que consagra de manera genérica el principio de mandato representativo - prohibiendo el mandato imperativo- y sin embargo, admite si no de derecho, sí de hecho, la vinculación de los representantes a las instrucciones de sus partidos políticos, porque aunque no exista una relación jurídica formal de mandato entre el grupo y sus parlamentarios, pesa sobre éstos el temor a posibles represalias si traiciona la disciplina de grupo, con lo que quiebra, en suma, el principio del mandato representativo que CONDORCET expresó brillantemente al afirmar: «Le peuple $\mathrm{m}$ 'a envoyé pour exprimer mes idées, pas les siennes, l'absolute indépendance de mes opinions, est le premier de mes devoirs envers lui».

Desde esta perspectiva cabe deducir una potenciación de la figura del grupo frente a la figura del parlamentario singular, que puede distorsionar los mecanismos de manifestación de la voluntad nacional, ya que el sentido del voto de los parlamentarios puede quedar condicionado por los intereses del partido político del que dependan.

En definitiva cabe afirmarse que la potenciación de los Grupos en el Parlamento grupal, se verifica a costa del parlamentario singular y con grave coste de su libertad de expresión a través del voto. Es desde esta consideración desde donde interesa partir para analizar el funcionamiento real del precepto 79-3 CE.

\section{FUNCIONAMIENTO REAL DEL PRECEPTO 79-3}

\section{El sistema de voto ponderado como exponente contra legem}

La regulación reglamentaria o estatutaria de la Cámara del Congreso y la práctica parlamentaria han conducido a la inaplicación del precepto

4 G. DI PALMA: Sopravivere senza governare. I partiti nel Parlamento italiano. Bologna, 1978, pág. 252.

5 A. TORRES DEL MORAL: «Los grupos parlamentarios», en R.D.P., n. ${ }^{\circ}$, Madrid, 1981, pág. 56. 
previsto en el 79-3 sobre el carácter personal indelegable del voto de Senadores y Diputados, a través del sistema de adopción de acuerdos en la junta de portavoces del Congreso previsto en el art. 39-4 RC.

A la luz de lo dispuesto en el precepto 79-3 $\mathrm{CE}$, ocupa una posición disonante el sistema de adopción de acuerdos que asume la Junta de Portavoces a través del voto ponderado, al conjugarse en este sistema precisamente los dos aspectos que contravienen la indelegabilidad y el carácter personal del voto de Diputados y Senadores. Esta afirmación puede predicarse extensivamente del supuesto de empate aparente en las votaciones en Comisión (art. 88-2 RC).

Efectivamente, en nuestro ordenamiento jurídico, a pesar de no haber sido regulado sistema alguno de adopción de acuerdos de este órgano ni en las Disposiciones dictadas por la Presidencia (art. 21-1), ni en los Reglamentos provisionales del Congreso y del Senado (arts. 27 y 17, respectivamente) ni en el Reglamento actual del Senado (art. 43), la práctica parlamentaria diseñó una orientación política ${ }^{6}$ poco coherente con la disposición constitucional del artículo 79-3 CE, en virtud de la cual los acuerdos se adoptarán por "unanimidad", y de no conseguirse ésta, por voto ponderado.

Por otra parte, la regulación reglamentaria del Congreso (art. 39-4), así como la reglamentaria autonómica prevén expresamente la adopción de acuerdos a través del voto ponderado.

\section{Su valoración en la doctrina}

La negativa valoración que la doctrina ${ }^{7}$ ha realizado sobre su aplicacion, cabe cifrarla en la circunstancia de haber apreciado en este sistema

- Acta 6 de septiembre de 1977: Incidentes en Santander con el Diputado Jaime Blanco. El Diputado Pérez Llorca plantea en la Junta de Portaveces cómo deben adoptarse los acuerdos.

Acta 26 de septiembre de 1977: Se hace constar en Acta, a petición del Diputado Guerra: "Haberse adoptado el acuerdo en la forma de practicar la votación por medio del voto ponderado, como criterio a seguir en lo sucesivo".

7 A. TORRES del Moral: Principios de Derecho constitucional español, vol. 2, Madrid, Átomo ed., 2. a edición, 1988, pág. 123.

R. Ripollés Serrano: "Comentario al art. 79-3», en Constitución Española 1978, tomo VI, Comentarios a las leyes políticas, Madrid, Edersa, Alzaga Villaamil, 1989, pág. 752.

E. ReCoder CASO: "Comentario al art. 79-3", en Comentarios a la Constitución, Fernando Garrido Falla, Madrid, Editorial Civitas, S.A., 1980. 
de voto una vulneración constitucional del artículo 67-2 CE, al considerar que contraviene la prohibición de mandato imperativo por una parte, y por apreciar asimismo una delegación del voto de los parlamentarios individuales en el portavoz de su grupo, contraviniendo así la prescripción constitucional del art. 79-3 CE.

A pesar de ser mayoritario el sector de la doctrina que sostiene esta posición, ha tenido contestación por otro sector ${ }^{8}$ al no ver en esta práctica parlamentaria vulneración de la prohibición del mandato imperativo (artículo 67-2 CE) por no existir relación jurídica formal de mandato entre el Portavoz y su Grupo, ni entre los miembros de base de los partidos y la Junta.

$Y$, por otra parte, tampoco considera que medie delegación de voto en tal práctica, ya que al no pertenecer los miembros de base a la Junta y no tener derecho al voto en la misma, difícilmente pueden delegar sus facultades en el portavoz del grupo.

\section{Su repercusión en el ámbito parlamentario}

Por otra parte, el criterio del voto ponderado ha originado un desacuerdo frontal de los grupos parlamentarios de la oposición, si bien es verdad que su desacuerdo lo cifraban no tanto en la desatención de la prescripción del art. 79-3 CE que se produce con la aplicación del voto ponderado, como por el resultado que se obtiene con este sistema de adopción de acuerdos, siempre beneficioso para el Gobierno cuanto éste cuenta con la mayoría absoluta del órgano plenario, en una función tan importante como lo es la determinación del Orden del día de los trabajos parlamentarios.

En todo caso, el Grupo Parlamentario Mixto (Agrupación PDP) presentó una proposición de ley de reforma del Reglamento del Congreso 9, pretendiendo la desaparición del voto ponderado, argumentando en su Exposición de Motivos: "... poner los medios adecuados para que los Diputados y los Grupos parlamentarios... tengan a su alcance controlar la acción del Gobierno en beneficio de la transparencia democrátican, pretendiendo con ello la restitución al diputado de base el carácter personal de su voto, al margen del Grupo.

8 I. Muro: Los órganos de gobierno de las Cámaras. Madrid, Congreso de los Diputados, 1987, pág. 292.

9 Proposición de Ley de Reforma del Reglamento del Congreso, BOCG de fecha 28 de febrero de 1987, serie B, ${ }^{\circ}{ }^{\circ}$ 54-1. 


\section{OPCIÓN POR UN SISTEMA DE VOTO PERSONAL E INDELEGABLE}

A pesar de no haber sido contemplado expresamente este precepto en el Derecho Comparado, a excepción de la Constitución Francesa 1958, art. 27, no nos parece innecesaria o inútil su expresa formulación, como lo demuestra el que a pesar de ella, se ha procedido a una regulación por vía reglamentaria que lo transgrede.

A la vista de lo que se ha señalado desde el punto de vista doctrinal y en el ámbito parlamentario, yo me inclino decididamente por la opción constitucional ofrecida en el art.79-3 CE, en torno a la personalización e indelegabilidad del voto de los Diputados y Senadores, llevándola, además, a sus últimas consecuencias, esto es, considerando que cualquier otra aplicación práctica parlamentaria sobre el sistema de voto que contradiga estos dos requisitos sería inconstitucional, lo cual sucede con el art. 39-4 del R.C. y 88-2 R.C. ${ }^{10}$.

En primer lugar, porque si la finalidad de tal sistema de voto ponderado en el caso del 39-4 RC tiene por objeto definir la ordenación de los trabajos parlamentarios, parece claro que se está partiendo del supuesto de delegación de votos de todos los componentes de la Cámara tanto en la figura de los Portavoces (39-4 RC), como en el número de quienes configuran la Comisión (88-2 RC) en los supuestos de empate en el seno de la misma.

En segundo lugar, porque frente a la tesis de quienes sostienen que no cabe hablar de delegación de voto en el sistema ponderado, al no pertenecer el parlamentario de base a la Junta de Portavoces y no tener derecho al voto en la Junta, me parece razonable pensar que el valor del voto de cada portavoz está en relación directa al número de parlamentarios con que cuenta cada portavoz en su grupo parlamentario, presumiendo el sentido del voto de dichos parlamentarios; en definitiva, delegación en suma por imperativo reglamentario.

En tercer lugar, porque con la personalización del voto se está subrayando el principio de imputación individual de la votación, esto es, la opinión de cada concreto individuo parlamentario, y no colectivamente a

10 No es éste el supuesto de las Comisiones con competencia legislativa plena (art. $148 \mathrm{RC}$ ) en el que se presume una delegación de competencia legislativa del Pleno. Delegación cuyo significado es según la acepción atribuida en el Vocabulario Jurídico de HenRI CAPITANT, 1981, Edic. Depalma, Buenos Aires, pág. 193: "Decisión por la que se confía a otro el ejercicio de una parte de su competencia». 
través de la suma de miembros con los que cuenta el colectivo del grupo parlamentario.

En cuarto lugar, en la esfera de la práctica parlamentaria, la autorización en vía reglamentaria del sistema ponderado para la adopción de acuerdos no justifica la despersonalización y delegación del voto de Diputados, derivada de tal práctica, ya que los Reglamentos de la Cámara no pueden contemplar ni aplicar disposiciones divergentes de los preceptos constitucionales.

Desde estas consideraciones llama la atención que un precepto aparentemente sencillo, que ni siquiera fue objeto de alteración en los trabajos constituyentes, y referido a una mera cuestión de orden en torno a las votaciones, contenga un componente sustancial de especial importancia del principio del mandato representativo que contempla el 67-2 CE.

Por lo que cabe afirmar, a mi parecer, que si bien los valores de operatividad, eficacia y disciplina de grupo se hacen precisos para el buen funcionamiento de los parlamentos actuales, no debe conseguirse esto a costa de las características del voto de los diputados y senadores: personalización e indelegabilidad, que se proyectan en definitiva como las garantías del principio de libertad en la formación de la voluntad nacional a través del voto de los diputados y senadores.

Todas estas razones esgrimidas son, a mi parecer, coherentes con la pretensión constitucional, lo que justifica mi opción por mantener el texto del precepto sin alteración, y sí, sin embargo, llamar la atención de lo conveniente que sería reformar el Reglamento del Congreso en lo que al sistema de voto ponderado concierne. 